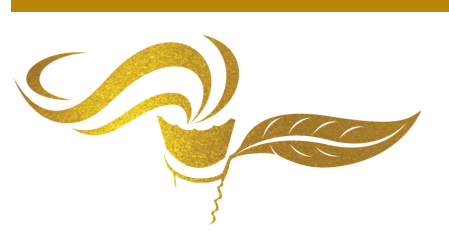

\title{
Complexity and Transdisciplinarity: The Case of Iconic Urban Megaprojects
}

\section{Gerardo del Cerro Santamaría}

Gerardo del Cerro Santamaría, Ph.D., Dr. Soc. Sci. U.S. Fulbright Award Recipient in Urban Planning, New York, European Union Expert Committee on Urban and Regional Policy, Email:gdelcerro@gmail.com

Received 2 November, 2019; Revised 10, January, 2020; Accepted 20 January, 2020

Available online 20 January, 2020 at www.atlas-journal.org, doi: 10.22545/2020/0131

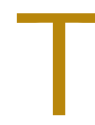

he nature and the shaping of urban megaprojects owes to the socio-economic, developmental, institutional and geographic context where they emerge. However, megaprojects, regardless of context, constitute disorderly, disruptive and contentious complexity and have an intrinsic potential (often realized) to elicit substantial controversy and criticism that fundamentally questions the parameters of the projects as envisioned and publicly presented by their promoters. As a result, it is possible to highlight as will be done in the conclusion to this paper - some suggestions for future research and policy practice aiming at urban sustainability that can be applied to the planning, design, management, implementation and development of megaprojects worldwide. Our proposal converges around transdisciplinary research on urban megaprojects. From the vantage point of transurbanism, the complex nature of megaprojects can be justly observed and assessed. In fact, the concept of complexity, which is salient in transdisciplinary approaches, suits research on urban megaprojects as characterized by disorder, disruption and contention.

Keywords: Urban megaprojects, complexity, transdisciplinarity, disorder, disruption, contention.

\section{Introduction: Transurbanism and the Outside}

Transdisciplinary urbanism is a proposal to focus on the reality of the outside both as a dimension of human experience and as a research strategy. This entails an ethical stand, that of noblesse d'espirit, that ought to drive our quest for knowledge and social change. The "reality of the outside" is not only the physical reality that embraces the city outside of urban megaprojects, but also the phenomenological reality of the knowing subject "being-in-the-world," and political reality outside of the priorities of elites that are never going to make the necessary efforts to improve society. The urbanism of the outside is a transdisciplinary endeavor enacted from multiple agencies, from the bottom up, from the margins to the center.

In recent years, citizen participation in urban planning processes has become both a demand and a reality. As the result of major economic crises around the world and growing awareness of the exploitation 
of the environment and climate change, disenchanted citizens have demanded to be more hands-on in deciding about and inuencing their living environments, while public authorities retaliate by drawing lines of jurisdiction. In the eld of architecture and urbanism, some have advocated for a radical change aimed at expanding design practice into a socially and politically relevant eld. Here the idea, put forward by Rizzo and Galanakis, is to develop a new urbanism education curriculum to include public-service practice, similar to the long-established curricula in law and medicine [1].

At the same time, in the heterogeneous eld of urban studies, many are starting to side with urban activists and artists to bring about the change that mainstream planning has failed to deliver. According to this view, public space has become the focus and location to organize artistic and cultural interventions that aim at questioning, amongst others, the current land use program, social and political injustice, and ultra-liberal privatizations of public commons. However, many questions arise about the use of art in urban studies, such as, how the extensive critical theoretical work on urban space and processes of urbanization of recent decades may further inform artistic practice, performance and intervention.

Within urbanism, several attempts have been made towards less reductive approaches to space and design; approaches that no longer choose between theory and practice as the ideal locus for critique, but, instead, allow critique to be processed in ways that are more complex and more entangled; approaches that advocate hybrid modes of inquiry. One can think of the hybridisation of nature and technology, engineering and the social, facts and values, human and non-human, and the explicit attention to agency in Science and Technology Studies (STS) and Actor-Network-Theory (ANT). Such approaches have in common their suggestion to approach urban issues not according to predefined ideologies or (critical) theories but to study them as a problem of the outside - as situated, complex gatherings of all sorts of agencies, where the notion of transdisciplinarity can be applied meaningfully.

We believe with Doucet and Janssens that, when countering the idea of design practice as a mere applied theory, and instead considering the architectural and urban question as hybrids, complex gatherings, and "messy undertakings," we should nevertheless not content ourselves with doing this alone. Both accountability and designerly, complex ways of understanding urbanism's agency in the world should be confronted with the fact that, no matter how well we develop tools to deal with it, and thus account (take responsibility) for such complex engagements, we will always be facing the contingency of design, a "leap in the dark." Namely, we can never entirely predict what the design itself will result in and what effect a design outcome will have, which unexpected agencies may enter, and what surprises we can enjoy [2].

Urban designers, despite insecurities about the effects of their actions, nevertheless act in a concerned manner and be held responsible for their actions. They ought to engage with the world in an irreductive, complex, and problematising manner rather than in a reductive fashion. In other words, they need to allow for surprises and with it "other possibilities" and, thus, "hope" as necessary elements for the enhancing of urbanism's projective capacity. No matter how well our design methods may become in order to deal with the complexity of the world, as soon as it starts to aim to control that complexity and contingency again, chances for the unexpected, for events to emerge, are constrained, and with it, any possibility for change. The answer to these challenges may be a transdisciplinary approach to urbanism that takes into account both the discovery (knowledge) dimension and the design (creation) dimension [3].

The common denominator of all approaches is an attempt to reconcile, exact sciences, social sciences, design and philosophy and advocate for a new transdisciplinary paradigm. The transdisciplinary framework envisioned here is similar to that suggested by Gibbons et al. in their "Mode 2 " of knowledge production, i.e. a dynamic framework in which multiple players combine empirical and theoretical knowledge to solve applied problems: a combination of knowledge and design, as discussed by Rizzo and Galanakis [4]. Dosse notes that the social sciences are witnessing "a genuine transformation" where terms such as chaos, process, meaning, complexity, and self-organization are slowly replacing the classic concepts of structure, static, combinatory, and universal. In this new framework, Dosse claims that the task of the transdisciplinary-scholar is to clarify, rather than dissect, the "judgments of fact" from the "judgments of value" [5].

Rizzo and Galanakis see Transdisciplinary Urbanism as a new, emerging methodological framework according to which social and action researchers from multiple fields, artists, animators, performers, 
activists, and local communities come together to study uncertainty, chance and open-endedness, and to transparently renegotiate power structures in urban space. Transdisciplinary Urbanism builds upon the social, philosophical and design aspects of Urbanism; it connects different theories and practices, and crosses disciplines in order to study and improve everyday life. The disciplinary crossovers entailed by such practices push inhabitants and professionals out from their comfort zones, encouraging co-operation and co-creation in non-predetermined ways [6].

Indeed, the exponential growth of both web-based interaction tools, physical sites where knowledge is created, and the recombination of extremely specialized elds in new knowledge entities have facilitated the emergence of a new form of knowledge production that Gibbons et al. have labeled "Mode 2," as mentioned earlier. As the opposite of "Mode 1", in which knowledge is eminently a contribution to compartmentalized disciplines, Mode 2 of knowledge production is characterized by transdisciplinarity, i.e. working within an evolving and dynamic framework in which empirical and theoretical knowledge are combined with design creativity and where multiple players (e.g., universities, research agencies, informal agencies, private rms, NGOs, etc.) contribute to the creation of such knowledge [7].

Transdisciplinarity can also be seen as an evolution of multi- and inter-disciplinarity. However, unlike these latter, transdisciplinarity does not seek to solve the paradoxes generated by the endless dissection of knowledge in smaller disciplinary units. Rather than aiming to the "unity of knowledge," by acknowledging the inherent complexity of the subject, transdisciplinarity directs to master the paradoxes. Building upon this, Transdisciplinary Urbanism (TU), urban studies and design provide the theoretical and empirical foundation to conduct proactive (but not pre-determined) investigation of the effects of change in urban space. TU researchers and the many actors working and living in the city work within the dynamic framework that is represented by contemporary polities, this latter shaped by unpredictable, constructive and destructive cycles.

\section{Transdisciplinary Research}

The process for transdisciplinary research in urbanism consists of three phases: problem identification, problem analysis, and bringing results to fruition. The designerly aspect has to do with the fact that these three stages do not necessarily occur in the given order, and with the fact that "bringing results to fruition" is not the same as problem-solving, and does not necessarily occur at the end of the research process. Rather, it takes place in the course of the research process in order to enable learning processes and is achieved in the form of a real-world experiment, which is, indeed, what an urban design can be considered to be.

In a context of hybrid knowledge among the exact sciences, the social sciences and philosophy, integration between theory and practice, ethical concerns, and the importance of experimental, designerly modes of inquiry become key to transdisciplinary urbanism. Transdisciplinary modes of knowledge production are characterized by hybridization, i.e. the loss of dependency from a specic disciplinary compartment. Transdisciplinary research includes at once what stands between disciplines, across disciplines and beyond any discipline. Transdisciplinarity is about the articulations, rather than the relations, between disciplines: the whole is more than the sum of its parts.

Because urbanism engages, both as a discipline and as a profession, with broader societal concerns (e.g. situated knowledge, participatory design, everyday practices), it therefore seems obvious that hybrid modes of inquiry are part of the knowledge landscape. In the context of this article we have used the broad understanding that, whereas interdisciplinary knowledge is located in scholarly environments, transdisciplinary knowledge production entails a fusion of academic and non-academic knowledge, theory and practice, discipline and profession.

Transdisciplinarity is a mode of inquiry, practice, and learning that places ethics, aesthetics, and creativity inside, not outside, of disciplinary and professional work. It brings new objects into view, places practices into new configurations, contextualizes and re-situates theory and learning, and incorporates social, political, and ethical questions once deemed beyond the proper sphere of research and education. 
The boundary work of transdisciplinarity is decidedly plural. It is generative, formative, and interrogative, catalyzing critique and transformations of our modes of inquiry, practice, and education.

Transdisciplinary urbanism ought to be inquiry-driven rather than exclusively discipline-driven; metaparadigmatic rather than intra-paradigmatic; informed by thinking that is complex, creative, contextualizing, and connective, following Edgar Morin [8]. Inquiry here is a process of creativity combining rigor and imagination. Transdisciplinarity is an attitude towards inquiry in urbanism, informed by certain epistemological presuppositions, and an effort to frame inquiry as a creative process that recognizes as central the subjectivity of the inquirer and challenges the underlying organization of knowledge. Problemdriven transdisciplinary urbanism investigates the interactions between the knowing subject and the object of knowledge. It encompasses discovery and creation, knowledge and design, science and creativity for a holistic interpretation of consciousness, space and social forces that includes theoretical, phenomenological and experimental concerns.

\section{Complexity and Transdisciplinarity}

The notion of "strategic urban planning" has become paramount in efforts to address a variety of challenges in urban environments. This notion involves a holistic approach to problem-solving that implies placing the idea of complexity at the forefront of analysis and action. Complex thought, education and knowledge, in Edgar Morin's understanding, take into account contextual, global and multidimensional factors to desvise strategy conducive to more fruitful action.

"Pertinent knowledge must confront complexity. Complexus means that which is woven together. In fact there is complexity whenever the various elements (economic, political, sociological, psychological, emotional, mythological ...) that compose a whole are inseparable, and there is inter-retroactive, interactive, interdependent tissue between the subject of knowledge and its context, the parts and the whole, the whole and the parts, the parts amongst themselves. Complexity is therefore the bond between unity and multiplicity. Developments proper to our planetary era confront us more frequently, ineluctably with the challenge of complexity." [9]

Complex knowledge also factors in the centrality of the knowing subject in analytical endeavors, the uncertainty of the knowledge enterprise itself and the incompleteness and undecidable nature of homo complexus's human action. Through complex knowledge, the holistic quality of urban planning neturally leads to a transdisciplinary conception of theory-building and practice development.

Thus, a possibly fruitful way to apply this notion of strategic urban planning would be to propose a transdisciplinary paradigm to address urban challenges that places complexity at the forefront of inquiry. Strategy by itself is insufficient if it is based on traditional approaches to knowledge generation. A global and transdisciplinary strategy of sustainable development that frames megaproject development is required.

The global problems of sustainable development consist not only in some of the environmental problems (generally known as climate change and loss of biodiversity), but also in socio-economic issues. Regardless of the possible and multiple interpretations of sustainability, it involves politics, resources and power. Most current attempts to solve sustainable development are not conducive to sustainable development; they are mostly contradictory, inconsistent and inefficient. This contrasts with the nature of the behavior of sustainable development systems, which is non-linear and holistic.

A transdisciplinary way of thinking is in order. Such a way of thinking would cross traditional disciplines and would modify the classical notion of science. A new vision fostering sustainable principles requires a rethinking of human values, and a reconsideration of the integration among the flow of perception, experience and consciousness. It is impossible to imagine a single solution to the problem of sustainability, but many complex, interrelated and evolving solutions. To avoid current destructive human behavior, we need to develop a new collective perception of human relations towards the valorization of a new set of attitudes and behaviors or towards a different prioritization of the set of current values. Holistic and unified knowledge can deal with complex global problems such as megaproject development within a sustainable development framework. 


\section{Urban Megaprojects}

For the past few decades, scholars have tried to make sense of an "urban moment" of increasing global attention to the relevance of cities for the evolution and development of nations. The unstoppable population growth in the cities of the planet has only intensified this interest in the urban realm. Cities are today analyzed as lenses through which we can observe and study the main socio-economic phenomena tied to globalization, which marks the evolution of humankind in the beginnings of the $21^{\text {st }}$ century. Further, cities are no longer understood exclusively as individual and discontinuous places, but rather as nodes in networks and flows of transnational capital, matter (goods and services), energy, information and people. Strategically positioning cities in the global network has become a major strategy of economic development for urban elites.

In order to increase their global visibility, many cities have undertaken in the past two decades strategies of revitalization and re-development that in many cases include the construction of emblematic megaprojects, often iconic buildings from an architectural point of view. The expectation was that such iconic buildings and structures would internationalize the city, put it "on the map", attract global investments, visitors and tourists, and thus contribute to solve the perennial problem of improving the welfare and prosperity of urbanites. The city of Bilbao, Spain, is a legendary example (one that is more successful than others) of this focus on urban development via construction of spectacular architecture in times of globalization.

We are heirs to the globalized city, in which it is not possible to conceive anything but the regeneration of areas adjacent to rivers and bays, the recovery of zones previously dedicated to storage and manufacturing, the construction of new transportation infrastructures or the extension of existing ones, as well as the renewal of historical centers. However, the Manhattanization of the world - and the urban political economy that sustains it - also presents difficulties and can create several structural obstacles with direct consequences for the design and implementation of megaprojects in globalizing cities and regions.

\section{Disorderly, Disruptive and Contentious Enterprises}

A case in point is Dubai, a megaproject set in crisis after the recession that started in 2008. After years in which one could regularly find news about the new architectural marvels of the world constructed in Dubai (including sets of artificial residential islands), the situation has been one of hypertrophy for this onetime urban vision. The bubble burst, and the model of Dubai became yesterday's news. Beginning in September 2008, real estate prices fell, and those who had gotten accustomed to positive news on the emirate were rubbing their eyes in disbelief. The glowing reviews about a permanent acceleration in megaproject construction - when Dubai was considered to be the dynamic and innovative center of the Arabic Peninsula - had turned into disbelief, first, and an admission of defeat not exempt of irony, later. The Emirate was bailed out by Abu-Dhabi, and the economic situation has improved in recent years, but a big weakness for Dubai remains: the city lacks a consistent concept of society, with more than $90 \%$ of its immigrants having very limited rights and unlikely to reside there permanently [10].

Situations of economic recession are only one of many obstacles faced by megaproject construction. Another is of a political nature, in particular the lack of strong metropolitan governments provided with the necessary instruments to undertake big projects that can transform the urban image and the urban fabric. Such is the case of Mumbai, which is determined to "Shanghaize" itself, although major challenges loom. Unlike in China - where the redistribution of local, regional, and national power has not been a zero-sum game in which the local governments have gained power at the expense of the central government the deliberate "Shanghaization" of Mumbai has seen the competition between different scales of government result in the concentration of power and resources at the metropolitan level, creating a power gap for the development of urban megaprojects. In China, the redistribution of power has taken place between the different levels, enabling the country to proceed with UMP construction and generally to better adapt to the requirements of the global economy [11].

The organizational obstacles in megaproject development are not minor. Bent Flyvbjerg (2003) already 
warned of these problems in Megaprojects and Risk with examples of big infrastructure projects in Europe [12]. The development of an urban megaproject is usually completed in various phases, and therefore many rearrangements, corrections, additions, and errors occur, not to mention the usual incapability by developers to limit the final expenses to the initial budget (so-called "cost overruns"). All this produces a lack of transparency that is increasingly difficult to support in view of the increasing activity of civil society, which organizes itself to face the ambitions of the political and economic elites. To cite some examples, megaprojects under construction in Budapest, New York, Paris, and Sao Paulo all illustrate the idea that, in the absence of clear and diaphanous planning - and although the state and the promoters try to explain the genesis and the impacts of the megaprojects - the whole process is perceived as dark and secret. Sometimes, this circumstance is used by the state to violate agreements and contracts of public interest and to reverse previous decisions, as has happened with the National Theater of Budapest, according to Judit Bodnar and Judit Veres (2013) [13].

We cannot forget either that sometimes UMPs develop in conflict situations - as shown by Alexandra Miller's work on the Afghan Ring Road (2013) - and that organized resistance to megaprojects can be of such a caliber that the state and the promoters fail to carry them out. This happened to Mexico City's proposed international airport project, which has been defeated because of the divisions between and within the political class and citizens initially triggered by the progressive democratization, decentralization, and globalization of the country. Diane E. Davis and Onésimo Flores Dewey (2013) argue that, in the Mexican case, it is also necessary to bear in mind the increasing power of the local state, which favors the civil opposition. The authors also underscore the importance of factors such as cultural identity, historical allegiances, and the geographical location in the mobilization of a wide array of local, national, and international allies against the airport [14].

A lesson of the Mexican case can be that bureaucratic ambiguities and tensions exist with regard to who is responsible for the principal projects of infrastructure in countries that experience a democratic transition. Such ambiguities and tensions can debilitate the proponents of a project and reinforce its opponents. This political and institutional baggage can also prevent urban planning authorities from learning how to respond to past experiences with citizen participation and civil opposition. Thus, the authors argue that the defeat of the airport megaproject in Mexico City was as much a reflection of a precarious moment in the political and economic development of the country as it was of the validity and legitimacy of the protests against the project itself.

Another contentious aspect of megaprojects is the planning, design and implementation of their iconic character, and the benefits that are assumed to be associated with such iconicity. Capturing a share of the world's mobile wealth is foundational to the justification of megaprojects. Protagonists embrace a narrative of international competitiveness, framing a project discourse that is dominated by the rhetoric of economic competitiveness for survival and development.

From an urban-spatial perspective, this entails that cities need to become "visible" and attractive to international capital. The "icon project" (Sklair, 2017), that is, the widespread construction of architectural icons in globalizing cities around the world, accomplishes these goals [15]. The construction of iconic urban megaprojects (IUMPs) has grown into a standard policy choice by urban and regional elites in globalizing cities. Politicians, business leaders and others in local and regional growth machines fulfill their personal and professional ambitions by investing in and promoting iconic urban megaprojects, aspiring to reach global status and positive economic change for their cities.

In what follows, we discuss contentious aspects in the planning and development of megaprojects in three cities around the world: Bilbao, Istanbul and Hong Kong. Our purpose is to lay out the variety of controversies, difficulties, obstacles, negative impacts and civic opposition associated to the construction of urban projects. We will show that the nature and the shaping of projects owes to the socio-economic, developmental, institutional and geographic context where they emerge. However, we will also see that urban megaprojects, regardless of context, constitute disruptive and contentious complexity and have an intrinsic potential (often realized) to elicit substantial controversy and criticism that fundamentally questions the parameters of the projects as envisioned and publicly presented by their promoters. As a result, it is possible to highlight - as will be done in the conclusion to this paper - some suggestions for future 
research and policy practice that can be applied to the planning, design, management, implementation and development of megaprojects worldwide.

\section{Shadows of the Bilbao Effect}

Many urban elites worldwide have been greatly influenced by the so-called "Bilbao effect" - the perception that the Guggenheim Museum Bilbao resulted in a "Cinderella transformation" of the Northern Spanish city and economic capital of the Basque Country. In the dominant discourse concerning architecture's surrender to capitalism's commercial goals, the Guggenheim Bilbao has been and remains to be mistakenly and repeatedly portrayed as the "catalyst" for the city's radically successful transformation from industrial powerhouse to regional service center. This case of disorderly, disruptive and contentious complexity (conceptual, planning, design, institutional and media complexity) has had many followers around the world.

For example, the new Ordos Art Museum in Inner Mongolia, beautifully designed by MAD, a prestigious firm of Beijing architects, suggests (not too surprisingly) that just building a terrific museum is not enough to ensure success. The city of Ordos has sprung up fast and is relatively wealthy, thanks to discoveries of oil and gas, but the museum has no collections and precious few plans for exhibitions. No wonder it is devoid of visitors. As Michael Kimmelman put it:

"The truth is, the Bilbao effect is largely a myth. Frank Gehry's museum alone didn't turn around that city. It capped decades of civic renewal. Flashy, even brilliant buildings rarely rejuvenate neighborhoods or guarantee crowds and cash just by virtue of their design [...] Sadly, museums, like cities, have squandered fortunes praying to this false idol. They still do." [16]

As I have shown elsewhere (Del Cerro, 2007), the Guggenheim Bilbao has been a positive addition to the city, but far from the 11miracle" that would turn Bilbao into a successful urban economy [17].

The debate on the "Bilbao effect" (how iconic megaprojects can successfully bring about urban transformation, development and competitiveness), however, continues. The Guggenheim in Abu Dhabi, scheduled to open in 2017 but still pending as of March 2019, will be twice the size of the museum in Bilbao, twelve times the size of the Frank Lloyd Wright Guggenheim in New York. Carol Vogel in The New York Times refers to this Gehry design as "a graceful tumble of giant plaster building blocks and translucent blue cones." [18] The outcome of the Guggenheim Helsinki's international competition was known in June 2015, with the winning project going to the Paris-based firm Moreau Kusunoki Architectes (by Fall 2016, the city of Helsinki voted against the project and construction never started).

These two projects have attracted significant criticism; they have been questioned along three main lines: (1) iconic architecture is no longer the hegemonic visual discourse in urban revitalization; (2) the franchise model imposed by the Guggenheim means that local officials have no autonomy to make major decisions on matters from exhibition calendars, to budgets and investments; and (3) local cultural identities are usually neglected under a foreign global arts model. In addition, the environmental impacts of the projects may not be negligible. The Abu-Dhabi project has also been controversial around issues of workers's rights and labor conditions. In spite of mounting criticism, if the new Guggenheim Museum in the United Arab Emirates results in even half the impact of that of Bilbao's, the term "Bilbao effect" will continue to carry weight on both sides of the debate.

Despite the media success of the Bilbao Guggenheim, the Bilbao effect has proven to be difficult to replicate in most places, even for Frank Gehry. On the other hand, some architectural icons, such as Gehry's Stata Center at MIT, work well with no Bilbao effect - most MIT scientists working in the building praise its playful and inventive feel (Campbell, 2007) [19]. Cooper Union alum Daniel Libeskind's jagged edges, sharp angles and complex geometries (the extension to the Denver Art Museum, the Royal Ontario Museum in Toronto or the Danish Jewish Museum in Copenhagen) have not had the universal acclaim of his Jewish Museum Berlin, an illustration that success, impact and visitor attraction are not necessarily a function of a building's spectacular design. Many works by Shigeru Ban or Tadao Ando are excellent 
examples of highly admired and successful architecture in the antipodes of iconic buildings designed to stun.

The jury is still out in 2019 regarding not only Gehry's highly anticipated Guggenheim Abu-Dhabi but also the massive West Kowloon Cultural District (WKCD) in Hong Kong, which stand among the most prominent cultural megaprojects in recent years. The WKCD is a project of such scale and ambition that it could "define the nature of the public realm in the 21st century," according to a rather hyperbolic statement by Rem Koolhaas (Koolhaas, 2013) [20]. The WKCD has met significant criticism from the planning to construction phases. Though a Guggenheim is not part of the project, the WKCD replicates all the expected controversies associated with IUMPs, including cost overruns, negative environmental impacts, gentrification risks, drawbacks of top-down cultural engineering, neglect of local cultural identities, and uncertain economic success, as we discuss below. None of these externalities bode well for cities that are counting on instant icons to salvage them during times of economic malaise.

\section{The Controversial Rebuilding of Istanbul}

Complexity in the Istanbul case involves not only the intricacies of city regeneration, but also, and fundamentally, the dialectics of political and economic power at the national level with the global image of Turkey and its chances at economic development being at stake. The process included local citizen resistance, political confrontations and the realignment of political options along the lines of a more environmentally-friendly Istanbul under Vision 2023.

When the Hali, or Golden Horn, a major urban waterfront and the primary inlet of the Bosphorus in Istanbul, started to be developed, there were views that the project would not yield significant economic benefits nor improve the quality of life of the residents, but would rather create a risk for gentrification of the urban area. The emphasis on creating shopping malls, parks, luxurious hotels and convention centres to attract tourists led to the demolishment of housing and the displacement of local populations. The Fener and Balat Rehabilitation Project is a good example of this phenomenon. The aim of this project was to improve the housing quality of the residents in the Fener and Balat area by providing 225 buildings with basic levels of comfort over a four-year period. It was started in 1997 with a joint intervention by the Fatih District Municipality, UNESCO and the European Union (Bezmez, 2008) [21]. Seventy percent of the buildings needed to be demolished due to their physical conditions, resulting in the removal of 900 families [22].

\subsection{Resistance from the Local Population}

In the Fener Balat Rehabilitation Project, although there have been measures taken by the government to prevent gentrification, such as excluding buildings that were bought after 1997 from the rehabilitation project and preventing owners from selling their properties within five years of completion of the restorations, the measures were vague and hence the local community still voiced out their dissatisfaction against the government. As Bezmez explains, there were several reasons for their protest. First, the idea that their houses were restored without any contribution from their part seemed unrealistic, making them fear that they were going to be gentrified and forced to cover the expenses. Second, most residents transformed the buildings such that a house could fit several families, therefore a return to the original building would provide them with much inconvenience. Third, a restriction that the residents could not sell their house in the next five years seemed impossible given their financial situation. Fourth, there were rumors that the project started with the intention to revive Istanbul's non-Muslim past and not to improve the living standards of the residents. Due to opposition of the project, the rehabilitation was halted and delayed [23].

\subsection{Political Confrontations}

When different mayors and parties were in charge of the Istanbul Metropolitan Municipality (IMM), the central government embraced different values and views towards the development of the Golden Horn, hence 
affecting the effectiveness and efficiency of development. In Mayor Dalan's term, the Turkish Clothing Manufacturers Association was interested in Feshane, a historical site of textile factories around the Golden Horn. The association was planning to use the building as an exhibition centre for the products of the association's members and also to rent out to exhibition organizers. The IMM would retain ownership of the building and rent it to the association on a long lease, therefore enjoying part of the profit. Dalan approved of this project hastily and even started restoration work before an initial agreement was signed.

However, the social-democratic mayor Nurettin Sozen was elected before Dalan could sign an official contract with the association, even if the association had already incurred significant expenses. As a result, Sozen called the operation to a halt by delaying the project with "every possible obstacle." At last, the association decided to give up the project. In the 1990s, the Eczacibasi Group, an industrial group in Turkey, wanted to turn Feshane into Istanbuls Museum of Modern Art. Similar to The Clothing Manufacturers Association, the Eczabasi Group was supposed to sign a long lease with the IMM and cover all the financial expenses of the redevelopment. Yet tension rose between the IMM and the industrial group after a plan including substantial expenses was put forward to restore Feshane. The project was abandoned [24].

\subsection{Vision 2023: Environmental Issues}

In 2017, Unesco declared Istanbul a "design city," pursued by the Turkish government as part of their "Vision 2023," which aims at the centennial of the proclamation of the Republic of Turkey. The threefold mega-development in Istanbul associated with the government's "Vision 2023" defines a set of goals centered around the further economic growth of the city and its nomination as a global hub. The first part of this development is Istanbul's Third Bridge in conjunction with the Northern Marmara Motorway. The second part consists of the Third airport situated in the North-West of the city, which is to become the world's biggest airport. In the same part also falls a plan concerning the development of a new city near the airport including multiple facilities (e.g. hotels, retail and commercial office space and logistic centers), which is to be connected with the existing city via high-speed underground and aboveground fixed-track infrastructure. The third part is Kanal Istanbul, located west of the Bosporus Strait, providing an alternative passage for vessels. This canal essentially bisects the European side of Turkey and creates a new island between Asia and Europe [25].

The above megaprojects represent serious challenges ranging from huge funding requirements, mostly undertaken by taxpayers, to significant impacts on urban structure, the natural environment and the community. As far as impacts on urban structure are concerned, according to Dogan \& Stupar, they are probable to be adverse by spoiling the visual and structural uniqueness of the city's environment and intensifying urban activities, leading to a further rise of population as well as a shift in urban density. The latter is expected to have synergetic effects with the construction of the Third Bridge, concerning the exacerbation of traffic congestion caused by the promotion of private vehicles [26].

The environmental issues are probably the biggest concern of this mega-development. The Third Bridge and its associated motorway passes through the northern border of the Belgrad Forest (adjacent to Istanbul) at the European side and the Bosporus Biodiversity Area, creating serious threats for a wide range of local habitats and intensifying the heat island effect. At the same time, noise and air pollution are expected to increase due to Istanbul New Airport (set to start in March, 2019, and with no official name yet due to political controversy), which is also to be placed on the migration routes of birds. The Kanal Istanbul is likely to trigger irreversible environmental disaster, taking into account the inversion of the hydrologic balance between the cold and fresh waters of the Black Sea and the warm and salty waters of Mediterranean Sea. Finally, the lack of community engagement as shown by the low level of public awareness of the above risks as well as the potential need for expropriations in order to empty lands for construction are characteristic of the impacts of this mega-development on the local community [27]. 


\section{The Business of Culture in Hong Kong}

Turning a city into a cultural capital is a complex endeavor. Complexity is here marked by image change, global media and the usual obstacles of design, planning and construction of facilities and infrastructure. Confrontations around contradictory political discourses with no convergence between stated objectives and actual intentions adds to the complexity surrounding cultural capital design and development. Moreover, damage to the environment by construction was a major factor that added to an already disruptive, disrderly and contentious scenario.

In spite of oficial statements about the focus on culture for Hong Kong's motivation in the West Kowloon Cultural District (WKCD), the project is viewed as largely focused on economic values, emphasizing tourism. The development of tourism has not been intended to promote culture, but instead to enhance Hong Kong as a 'traditional economic stronghold' as declared by the first Chief Executive of Hong Kong Special Administrative Region (HKSAR) Tung Chee-wah. He stated in his 1998 policy speech, during an economic crisis in Hong Kong, that it was the government's plan to distinguish Hong Kong as 'Asia's world city' and 'Asia's entertainment capital' through megaprojects. After the Asian financial crisis in 1997-99, the "promised" outcomes of megaprojects, as shown in Bilbao, Pittsburgh, Baltimore and other cities attracted Hong Kong leaders [28].

\subsection{Developers and Politicians}

Populist politicians in Hong Kong denounced the early versions of the plan as too generous to developers. Tung Chee-hwa, the Chief Executive of Hong Kong, initially planned to hand over the entire project to one large developer as expressed in his annual policy address. The plan was decried as a subsidy to the city's wealthiest developer, Li Ka-shing. Even many of Tung's longtime allies among business leaders did not support him in his plan for the WKCD. The plan was revised in October 2005, calling for a lead developer to build half of the residential and commercial real estate on the WKCD Peninsula, while other developers could bid for the rest. The revised rule was objected by the three wealthy developers who submitted proposals under the initial rules [29].

The project was also criticized as property development rather than cultural project due to its connections to the large scale retail industry as well as commercial and residential development interests (Sum 2010). The government funding primarily supports shopping, dining and entertainment facilities with expectation of revenues, which is beneficial to the city's wealthy developers. Not surprisingly, raising prices of properties in the neighborhoods could be detected as early as 2010, and continue today [30].

\subsection{Academic Opinions of the Project}

The WKCD project is a controversial megaproject, which seeks to globalize Hong Kong as an art hub city. Professor Tai-lok Lui, as many scholars who criticize the WKCD project, describes the proposal as an example of entrepreneurialism and neo-liberalism:

"The proposal was a typical package of urban entrepreneurialism, with an emphasis on chasing after mega-projects, iconic buildings and media visibility. But it avoided questions concerning the substance of the entire project, consensus from below and the vision of cultural development. Its failure shows that, without addressing these basic questions, city competition by means of developing global architecture, mega-projects and fabricated urban culture is inevitably futile." [31]

Helen Siu and Agnes Ku, Sociology professors at the Hong Kong University of Science and Technology, examined the WKCD project and the Hong Kong's attempt to build a "global city." They explain the relationship among different sectors involved in the project with the local institutional structure and processes, defined by "the cultural policy and institutional framework in colonial times - characterized by non-interventionism and top-down drive under a fragmentary yet centralized structure." [32] Siu and 
$\mathrm{Ku}$ articulate that top-down decision-making structures and the lack of voice from cultural practitioners under globalization has undermined cultural citizenship and civil society in the dominant discourse of globalization. For instance, the People's Panel on West Kowloon (PPWK) was set up by activists in the cultural sector and civic organizations to re-examine the project, seeking cooperation among government, property developers, and civil society. Yes, this Panel never became operative.

Moreover, some scholars point out that the WKCD has already failed to "globalize" Hong Kong, as the project has largely ignored the history, culture and identity of the city. The Brand Hong Kong program of which WKCD is part bears the mission "to provide a greater focus to the international promotion of Hong Kong as 'Asia's world city." ' The marketing strategy of the city's Brand Hong Kong program has, in its preoccupation with these values, marginalized others, according to Stephen Chu. The Donald Tsang administration was keen on developing Hong Kong into a hub of Asian creative industries, but not a base for local creative industries to grow in. As long as the development of creative industries is being framed by the "Brand Hong Kong" concept, vernacular hybrid cultures and spaces cannot surface (Chu, 2010) [33].

"The overwhelming emphasis on branding Hong Kong has ironically led to the loss of Hong Kong's intrinsic uniqueness: the blending of the global and the local into a hybrid emerging culture which is significantly 'glocal." [...] "It attempts to assess the implications of the Brand Hong Kong program's failure in recognizing that the distinguishing characteristic of Hong Kong was its emergent community where genuine cosmopolitanisms found the space to emerge." [34]

\subsection{Environmental Impacts}

The WKCD is constructed by reclamation of the Victoria Harbor. It was initially a trading harbor, and eventually became a tourist spot and an important transit path between the Kowloon Peninsula and Hong Kong Island. The Victoria Harbor provides a natural scenic asset to Hong Kong, claiming itself to be the "Pearl of the Orient" by the panoramic view seen from airplane windows or skyscrapers in Hong Kong. The Victoria Harbor has attracted 55\% of the tourists coming to Hong Kong in recent years (Chan, 2000) [35]. Reclamation activities became intensified since the 1980s. The amount of land reclaimed from $2000-2005$ is equivalent to the amount of land reclaimed in the last 100 years, and significant pieces of land reclaimed include 250 hectares of land for container terminals in the port.

The West Kowloon Project has reclaimed 40 hectares of land around the Victoria Harbor [36]. During the construction phase it was expected "construction site runoff, pumped groundwater discharge, drainage diversion, sewage effluent and accidental spillage that contain high levels of suspended solids and chemicals such as oils, solvents and cement-derived materials." [37] The process of dredging is needed to remove unsuitable foundation and replace with large volumes of dredged sand, exacerbating water pollution in Hong Kong. Dredging reduced primary productivity in the sea, affecting the marine ecosystem since they are dependent on plants for sustenance [38]. There is also a loss of sensitive species such as filter-feeding organisms, including scallops, mussels and oysters, which are essential to a vibrant seafood business around Hong Kong. There is also evidence that the Chinese White Dolphins, which is an endangered species unique to Hong Kong, is threatened since dredged materials compromise the well-being of Dolphin Sanctuary neighboring to East Sha Chau Contaminated Mud Pit, where the dredged contaminated mud is disposed of. There are only 85 Chinese Pink Dolphins out of the original 300, and those that survived were not expected to survive further reclamation [39].

\subsection{Poor Air Quality}

The WKCD is located next to the Western Tunnel Crossing, which connects West Kowloon across the harbor to Hong Kong Island and is one of the busiest locations in Hong Kong. It has one of the worst air qualities with average PM 2.5 concentration around the tunnel crossing at 63 micrograms/cubic meter, which far exceeds the World Health Organization's (WHO) air quality maximum threshold of $25 \mathrm{mg} / \mathrm{m}^{3}$. During construction, activities such as excavation, stockpiles, the movement of vehicles, concrete batching 
and the activities of other plants during the loading and unloading operations added onto the already poor air quality around the area [40].

Other major infrastructure construction, such as the Western Harbor Crossing portal, the additional roads and car parks with the WKCD are also affecting the air quality surrounding the area. Since the newly reclaimed land would also accommodate for large number of people during mega events, the resulting pollution, traffic congestion and over-concentration will also aggravate the existing air pollution problem $[41]$.

The project promised to build better landscape in the surrounding area of WKCD, including additions of ornamental plants, a piazza, park and avenue through innovative design. Yet, the effects of greening the space might not be able to compensate for the other landscape impacts. For instance, along with the nearby Kowloon MTR station, Elements Mall International Commercial centers and several enormous apartment buildings are being constructed. Further plans show the construction of skyscrapers in the WKCD, further obstructing the view of the Victoria Harbor [42].

\section{Conclusions}

This paper has presented and discussed evidence in three cities (Bilbao, Istanbul and Hong Kong) showing that megaprojects are disorderly, disruptive and contentious enterprises triggering important economic, sociopolitical and environmental challenges that are often hard to resolve for the benefit of urban communities. The list is long: cost overruns, negative environmental impacts, gentrification risks, drawbacks of topdown cultural engineering, neglect of local cultural identities, an uncertain economic success, population displacements, the spoiling of citiesvisual and structural uniqueness, rise of congestion and overpopulation, political gridlock, threats for ecosystems, environmental risks of many kinds, etc.

In view of all of these drawbacks, it seems reasonable to think that better investment opportunities exist for cities, but very often these opportunities are not priorized given the hegemonic neoliberal urban discourse that focus on growth, international visibility and competition in the global arena.

Under the "green capitalism" label, recent megaprojects are presented as "sustainable." However, it remains unclear under what conditions these allegedly sustainable megaprojects can foster widespread growth and shared prosperity. Will they simply symbolize, once again, the grandiose vision of political and economic leaders in their attempta at nation-building to effectively compete on the global board? Will those megaprojects yield economic benefits to the cities that host them and not only to the promoters who build them? We do not know yet, although there is growing evidence that the benefits could be very limited (as is increasingly the case with Olympic mega-events).

Growing skepticism about spectacular and large-scale urban development, as well as the multiple impacts of the Great Recession of 2008, have triggered a rethinking of urban revitalization strategies in the West, and new paradigms, such as "smart cities," have come to the forefront of the discussions. Advocates of the "smart city" idea, who rightly stress the importance of digitalization and technology for a better management of urban areas, seem to overlook the fact that it is the governance models, not just the tools, that need to be improved.

What is truly fundamental for urbanites is to ensure that their leaders (and themselves as creators and re-creators of the places they inhabit) work to organize sustainable urban ecosystems from an ecological, environmental and socio-economic perspective. The good form and efficiency of the city are not enough to guarantee a good urban life. Improving macro-economic magnitudes is not enough if there is no effort at achieving higher levels of social welfare. Urban visibility (megaprojects) and urban connectivity (smart cities) strategies, by themselves, present as many risks as benefits for urban populations.

Jane Jacobs rightly reminded us almost half a century ago that cities are organized complexity that can not be addressed as a conventional problem of hierarchies and visual or mechanical order planned exclusively by leaders and experts (her diatribes with Robert Moses, the great modernizer of New York, are legendary). Jacobs understood cities as a complex problem of interrelated factors in an organic whole, and recommended urban planners and architects to show respect for the intrinsic order of the city and 
discard the demiurgic, spectacular and traumatic interventions that they often put into practice.

Today, the science of complexity applied to urbanism is proposing some postulates based on scientific evidence and the multidisciplinary study of cities that echoes the thought of Jacobs. The first is that cities have the capacity to promote creative and dynamic growth and at the same time reduce the destruction of resources. It has long been known that the city is more efficient than other types of human settlements from the point of view of energy, consumption of resources and emission of greenhouse gases. The reason is that urban ecologies are organized through exchange networks organized in spatial proximity whose synergies have positive and multiple effects. In other words, cities are complex, dynamic and variable human clusters that can favor efficiency, competitiveness and ecology.

Likewise, we know that networks and proximity flows and casual encounters in defined spatial environments foster multiplier effects and thus explain the impact of creativity on the economic strength of cities. We are not advocating for the presence of a creative class that allegedly serves as as the engine for urban prosperity, but rather for valuing and promoting the configuration of the ecological character of the city as a place for the exchange of knowledge, information, experiences and affections. This area of exchange needs public or semi-public spaces, and hence the crucial importance of preserving squares, sidewalks, parks, terraces, cafés and other meeting places where economic rationality does not prevail. Online connections can supplement, but not replace, this primary network of face-to-face human exchange.

Like any network, cities benefit geometrically from the number of existing connections. If the economic disparity between urbanites condemns certain citizens and neighborhoods to socio-spatial segregation, the prosperity of the city as a whole will be compromised. For reasons of social welfare, economic prosperity, and, increasingly, for reasons of survival of the planet and our species, it is essential to advance in the planning of integrated cities on a human scale that respect the close and multiple interaction of their neighborhoods. This constant process of human interaction - the intrinsic order of the city - allows urbanites to shape their own identity by appropriating their environment and endowing it with meaning, a fundamental factor that contributes to individual and collective well-being, and indirectly also to prosperity.

Cities need to ensure that the above ideas, which flesh out the urban order as organized complexity, become the driving force behind megaproject planning and implementation. When urban ecologies are organized through exchange networks organized in spatial proximity, when urban planning values and promotes the configuration of the ecological character of the city as a place for the exchange of knowledge, information, experiences and affections, and when planning aims at advancing integrated cities on a human scale that respect the close and multiple interaction of their neighborhoods, then megaprojects could possibly work for the welfare of the community; at a minimum, they would turn from disorderly, disruptive and contentious enterprises into feeble artifacts.

Funding: This research received no external funding.

Conflicts of Interest: The author declares no conflict of interest.

\section{References}

[1] Rizzo, A. and M. Galanakis (2015). Transdisciplinary Urbanism: Three Experiences from Europe and Canada. Cities, 47, 3544 .

[2] Doucet, I. and Nel Janssens (2011). Transdisciplinary Knowledge Production in Architecture and Urbanism. Towards Hybrids Modes of Inquiry, London: Springer, p. 156.

[3] Ibid. p. 178.

[4] Gibbons, M., Limoges, C., Nowotny, H., Schwartzman, S., Scott, P., \& Trow, M. (1994). The New Production of Knowledge: The Dynamics of Science and Research in Contemporary Societies, San Francisco: SAGE; I follow the discussion by Rizzo, A. and M. Galanakis (2015) "Transdisciplinary Urbanism: Three Experiences from Europe and Canada," Cities, 47, 3544.

[5] Dosse, F. (1999).Empire of Meaning. The Humanization of the Social Sciences, Minneapolis: University of Minnesota Press, p. 23. 
Gerardo del Cerro Santamaría

[6] Rizzo and Galanakis, Ibid.

[7] Gibbons et. al, Ibid. pp. 5-6.

[8] Morin, Edgar (2005). On Complexity. Cresskill, NJ: Hampton Press.

[9] Morin, E. (1999). Seven Complex Lessons in Education for the Future, Paris: UNESCO, p. 19.

[10] Elsheshtawy, Y. (2009). Dubai. Behind an Urban Spectacle, London:Routledge; Chan, K. (2015) Competitiveness to Transform Dubai into a Global City. Presentation to World Strategy Summit, Abu Dhabi http://www.kailchan.ca/wp-content/uploads/2016/01/Kai-Chan_WSS-Dubai-a-global-competitivecity_18-Nov-2015_v5.pdf. (Accessed September 21st, 2019).

[11] Weinstein, L. And X. Ren (2009). The Changing Right to the City. Renewal and Housing Rights in Globalizing Shanghai and Mumbai, City \& Community 8 (4) 407-432. https://doi.org/10.1111/j.1540-6040.2009.01300.x. (Accessed October 1st, 2019).

[12] Flyvbjerg, B., Bruzelius, N., Rothengatter, W. (2003). Megaprojects and Risk: An Anatomy of Ambition, London: Cambridge University Press.

[13] Bodnar, J. and J. Veres (2013) The Petty Politics of an Urban Megaproject in Budapest, in Del Cerro Santamara, G., ed. (2013). Urban Megaprojects. A Worldwide View, Bingley, UK: Emerald Group Publishing Limited

[14] Miller, A. (2013) The Afghan Ring Road Megaproject, in Del Cerro Santamara, G. Ed., Urban Megapeojects. A Worldwide View, Bingley, UK: Emerald Group Publishing Limited; Davis, D. E. and Onésimo Flores Dewey (2013). How to Defeat an Urban Megaproject. Lessons from the Mexico City Airport Controversy, in Del Cerro Santamara, G. Ed. Urban Megaprojects. A Worldwide View, Bingley: Emerald.

[15] Sklair, L. (2017). The Icon Project. Cities, Architecture and Capitalist Globalization, New York: Oxford University Press.

[16] Kimmelman, M. (2012) Why is This Museum Shaped Like a Tub? The New York Times, Art and Design Section, December 23, p. 31, http://www.nytimes.com/2012/12/24/arts/design/ amsterdams-new-stedelijk-museum.html?_r=0 (Accessed October 4th, 2019).

[17] del Cerro Santamaria, G. (2007). Bilbao. Basque Pathways to Globalization, London: Elsevier.

[18] Vogel, C. (2014). A New Art Capital, Finding Its Own Voice. New York Times, December 6th. http://www.nytimes.com/2014/12/07/arts/design/

inside-frank-gehrys-guggenheim-abu-dhabi.html?_r=0 (Accessed October 5th, 2019).

[19] Campbell, R. (2007). Does Gehry's Stata Center Really Work? Bloomberg Business, June 19, http://www.bloomberg.com/bw/stories/2007-06-19/does-gehrys-stata-center-really-work-businessweekbusiness-news-stock-market-and-financial-advice (Accessed October 7th, 2019).

[20] Koolhaas, R. (2013). quoted in Dunham-Jones, E. The Irrational Exuberance of Rem Koolhaas, Places Journal, April https://placesjournal.org/article/the-irrational-exuberance-of-rem-koolhaas/ (Accessed October 11th, 2019).

[21] Bezmez, D. (2008). The Politics of Urban Waterfront Regeneration: The Case of Hali (the Golden Horn), Istanbul, International Journal of Urban and Regional Research 32 (4) 815-40.

[22] Columbia University (2015). Istanbul: Planning for Transparency and Inclusion, http://www.arch.columbia.edu/files/gsapp/imceshared/Istanbul_Final_Report_Spread.pdf (Accessed April 26th 2018).

[23] Bezmez, Ibid., p. 823.

[24] Bezmez, Ibid., passim.

[25] Dogan, E. \& A. Stupar (2017). The limits of growth: A case study of three mega-projects in Istanbul, Cities, 60 Part A, 281-288, p. 284.

[26] Ibid, p. 286.

[27] Ibid, p. 287.

[28] Lui, P. (2008). Privatizing the Hong Kong Special Administrative Region Government: Revisiting the Case of The Link REIT from a Policy Network Perspective, presented at The International Conference on Promoting City Competitiveness, October 24, 2008 at Chung Hua University, Hsin Chu City, Taiwan. 
[29] Bradsher, K. (2006). Hong Kong Halts Plans for Arts Center. The New York Times. February 22nd, http://www.nytimes.com/2012/01/25/world/middleeast/abu-dhabi-reaffirms-its-grand-plan-formuseums.html (Accessed May 27th, 2018).

[30] Lau, J. (2011). A Bid for Culture in a City of Commerce. The New York Times. June 6, http://www.nytimes.com/2011/06/07/world/asia/07iht-hong07.html (Accessed May 23rd, 2018).

[31] Lui, P. (2008). Privatizing the Hong Kong Special Administrative Region Government: Revisiting the Case of The Link REIT from a Policy Network Perspective, presented at The International Conference on Promoting City Competitiveness, October 24, 2008 at Chung Hua University, Hsin Chu City, Taiwan, p. 82.

[32] Siu, H. and A. Ku (eds) (2008). Hong Kong Mobile: Making a Global Population. Hong. Kong University Press, p. 83.

[33] Chu, Stephen Yiu-wai (2010). Brand Hong Kong: Asia's World City as Method? Visual Anthropology, Volume 24, Issue 1-2.

[34] Ibid. P. 46.

[35] Chan, Y. (2000). Reclamation and Pollution in Hong Kong with Special Reference to Victoria Harbour. The HKU Scholars Hub, http://hdl.handle.net/10722/36319 (Accessed October 16th, 2019).

[36] WKCDA (2013). Annual Report, http://www.westkowloon.hk/en/the-authority/annual-report-20122013 (Accessed June 24th, 2018).

[37] Ibid., p. 33.

[38] Chan, Ibid., p. 47.

[39] Ibid., p. 49.

[40] Clean Air Network (2018). Clean Air Network Response to Policy Address, http://www.hongkongcan.org/hk/press-release/ (Accessed October 23rd, 2019).

[41] Chan, Ibid., p. 51.

[42] Dewolf, C. (2011). The future of Hong Kong's harborfront. CNN, October 24, http://travel.cnn.com/hongkong/life/future-hong-kong-129384 (Accessed October 29th, 2019).

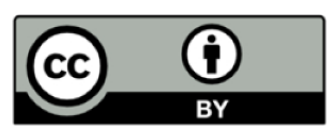

Copyright (c)2019 by the author. This is an open access article distributed under the Creative Commons Attribution License (https://creativecommons.org/licenses/by/4.0/), which permits unrestricted use, distribution, and reproduction in any medium, provided the original work is properly cited.

\section{About the Author}

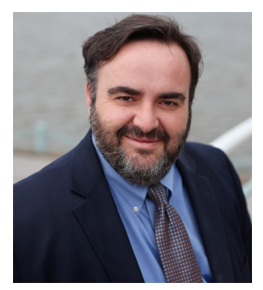

Gerardo del Cerro Santamaría is a U.S. Fulbright Award Recipient in Urban Planning from New York and a member of the European Union Expert Committee on Urban and Regional Policy. He has been a Visiting Professor at MIT and a Visiting Scholar at Columbia University, as well as Research Professor of Planning and Megaprojects at The Cooper Union for the Advancement of Science and Art in Manhattan, where he also served as Senior Executive Director of Strategic Planning and Innovation. He has been an 
Invited Professor of Urbanism and Globalization at the School of Architecture and Planning, Shenyang Jianzhu University and served as a Senior Advisor to the Planning of the Jing Jin Ji Megalopolis in China. Del Cerro has published several books, journal articles and encyclopedia entries. He is the author of Bilbao. Basque Pathways to Globalization (2007); editor of and contributor to Urban Megaprojects. A Worldwide View (2013); and author of "Megaprojects in Global Context" in The Oxford Handbook of Megaproject Management (2017). He has a background in Science, Music Theory, Logic and Philosophy of Science and holds Ph.D.'s from the New School for Social Research in New York (Political Economy) and the Universidad Autónoma de Madrid, Spain (Economic Sociology). 